\title{
Demand elasticities for different food items in Bangladesh
}

\begin{abstract}
To identify the magnitude of food demand which would be helpful for demand projection and to assist government planning authority and researcher present study was under taken. The study estimated demand elasticities for different food items in the context of Bangladesh by using Almost Ideal Demand System (AIDS) model with corrected Stone Price Index. The income elasticity of demand for cereal, pulse, edible oil, vegetable, fish, meat, fruit, milk and spices were $0.51,0.72,1.77,0.50,1.30,2.46,1.96,1.86$ and 1.60 , respectively. The compensated and uncompensated own price elasticity indicated that all food items (except edible oil and spices) were price inelastic. The estimated uncompensated own-price elasticity of demand for cereal, pulse, edible oil, vegetable, fish, meat, fruit, milk and spices indicated that if the price fell by $10 \%$ then the demand for cereal, pulse, edible oil, vegetable, fish, meat, fruit, milk and spices would increase by 2.73, 7.25, 13.92, 3.14, 4.32, 6.70, 6.11, 3.45 and $14.47 \%$, respectively. The estimates of cross price elasticity indicate that substitution effects of price change were not quite strong. Consequently government price interventions may not lead to considerable price repercussions in the economy. Simultaneously no systematic differences in the absolute magnitudes of the expenditure elasticity and own price elasticity were found. This implies that a combination of income and price policies may be more effective in influencing consumption pattern than those based solely on an individuality basis without taking into consideration the other factor.
\end{abstract}

Keyword: Food demand; Income elasticities; Price elasticities 